\title{
GAMBARAN KEJADIAN NYERI LUTUT DENGAN KECURIGAAN OSTEOARTRITIS LUTUT PADA PERAWAT DI POLIKLINIK RAWAT JALAN BLU RSUP. PROF. DR. R. D. KANDOU MANADO
}

\author{
${ }^{1}$ Rita Purnama Deu \\ ${ }^{2}$ Th. Isye Mogi \\ ${ }^{2}$ Engeline Angliadi \\ ${ }^{1}$ KandidatSkripsi Fakultas Kedokteran Univerversitas Sam Ratulangi Manado \\ ${ }^{2}$ Bagian Ilmu Kedokteran Fisik dan Rehabilitasi Fakultas Kedokteran \\ Universitas Sam Ratulangi Manado \\ Email: rita_deu@yahoo.com
}

\begin{abstract}
Osteoarthritis (OA) is adegenerativejoint diseaseassociatedwith thedestructionof joint cartilage.OA canoccur in all joints of the cervical, thorakal, lumbar, pelvis, knees, ankles, hands up to the fingers, most commonly found in the knee joint because these joints can load larger than the other joints. OA patients usually complain the pain at the time of doing the activity or if there is load on the affected joint. On a more serious degree of pain can be felt continuously until it is very disturbing patient mobility. The purpose, to find numbers of EventOverview Of KneePainBySuspicion on Nurses' Knee Osteoarthritis At Outpatient Treatment In BLU Polyclinic Prof. Dr. R. D. Kandou Hospital. Methods: This study used a descriptive quantitative approach. Sample was on 25 nurses. Data were obtained through interviews and questioners and then analyzed by using SPSS. Conclusion: From the research that the highest numbers of nurses on suspected knee OA are in the age group 51-60 years by 14 nurses $(56.0 \%)$. By sex that nurse in knee OA is suspected that as many as 23 female nurses (92.0\%). Based on the BMI (Body Mass Index) most of the nurses which at obese I are 13 nurses (52.0\%). Based on the degree of knee pain most of the nurses experienced mild pain as many as 19 nurses (76.0\%). Based on the Lequesne index functions mostly mild functional at 13 nurses (52.0\%). Based on the use of high heel shoes most of the nurses women using high heel shoes by 19 nurses (76.0\%). Based on other activities such as going up and down stairs 15 nurses who "not" 10 nurses and 25 nurse long standing activity (100\%).
\end{abstract}

Keywords: A number of events, Knee Osteoartritis , knee Pain, Lequesne Index Parameters, BMT (Body Mass Index), VAS (Visual Analog Scale).

Abstrak: Osteoartritis (OA) merupakan penyakit sendi degeneratif yang berkaitan dengan kerusakan kartilago sendi. OA mengenai semua persendian dari servikal, thorakal, lumbal, panggul, lutut, pergelangan kaki, tangan sampai ke jari-jari, paling sering ditemukan pada sendi lutut karena sendi-sendi ini dapat pembebanan yang lebih besar dibanding sendi-sendi yang lain. Pasien OA biasanya mengeluh nyeri pada waktu melakukan aktivitas atau jika ada pembebanan pada sendi yang terkena. Pada derajat yang lebih berat nyeri dapat dirasakan terus menerus sehingga sangat mengganggu mobilitas pasien. Tujuan, untuk mengetahui angka kejadian Nyeri Lutut dengan kecurigaan OA lutut pada Perawat di Poliklinik Rawat Jalan BLU RSUP Prof. Dr. R. D Kandou Manado. Metode Penelitian : Penelitian ini menggunakan pendekatan deskriptif kuantitatif. Sampel berjumlah 25 perawat . Data diperoleh melalui kueisioner dan wawancara kemudian dianalisis 
menggunakan SPSS. Simpulan: Dari hasil penelitian bahwa perawat yang di curigai OA lutut terbanyak pada kelompok umur 51-60 tahun sebanyak 14 perawat (56,0 \%). Berdasarkan jenis kelamin perawat yang di curigai OA lutut adalah perempuan yaitu sebanyak 23 perawat (92,0 \%). Berdasarkan IMT (Indeks Massa Tubuh) sebagian besar perawat adalah obese I yaitu 13 perawat (52,0 \%). Berdasarkan derajat nyeri lutut sebagian besar mengalami nyeri ringan yaitu sebanyak 19 perawat (76,0 \%). Berdasarkan indeks lequesne sebagian besar fungsi fungsional ringan yaitu 13 perawat (52,0 \%). Berdasarkan pemakaian sepatu tumit tinggi sebagian besar perawat perempuan. menggunakan sepatu tumit tinggi sebesar 19 perawat (76,0 \%). Berdasarkan aktivitas lain seperti naik turun tangga 15 perawat yang "tidak" 10 perawat dan aktivitas berdiri lama 25 perawat (100\%).

Kata Kunci : Gambaran angka kejadian, Osteoartritis lutut, Nyeri lutut, Parameter Indeks Lequesne, VAS ( Visual Analog Scale).

Osteoartritis (OA) merupakan penyakit sendi degeneratif yang berkaitan dengan kerusakan kartilago sendi. OA mengenai semua persendian dari servikal, thorakal, lumbal, panggul, lutut, pergelangan kaki, tangan sampai ke jari-jari, paling sering ditemukan pada sendi lutut karena sendi-sendi ini dapat pembebanan yang lebih besar dibanding sendi-sendi yang lain. Prevalensi OA di SMF Rehabilitasi Medik BLU Prof. Dr. R. D. Kandou Manado cukup tinggi yaitu mencapai 19\% pada tahun 2012. OA termasuk penyakit terbesar dan menempati urutan ke tiga setelah stroke dan LBP (Low Back Pain). Di Indonesia, prevalensi osteoartritis cukup tinggi, yaitu mencapai 15,5\% pada pria, dan $12,7 \%$ pada wanita. ${ }^{1}$

Berdasarkan patogenesis dari osteoatritis dibedakan menjadi dua yaitu osteoartritis primer dan osteoartritis sekunder. Osteoartritis primer disebut juga osteoartritis idiopatik yaitu osteoartritis yang kausanya tidak diketahui dan tidak ada hubungannya dengan penyakit sistemik maupun proses perubahan lokal pada sendi. Osteoartritis sekunder adalah osteoartritis yang didasari oleh adanya kelainan endokrin, inflamasi, metabolik, pertumbuhan, herediter, jejas mikro dan makro serta imobilisasi yang terlalu lama. $^{2}$

Terjadinya osteoartritis dipengaruhi oleh faktor-faktor resiko yang tidak dapat diubah yakni faktor genetik, jenis kelamin, suku/ras dan usia. Dan faktor-faktor resiko yang dapat di modifikasi yakni obesitas, hormonal, aktivitas fisik dan trauma/cedera. ${ }^{1}$

Pasien OA biasanya mengeluh nyeri pada waktu melakukan aktivitas atau jika ada pembebanan pada sendi yang terkena. Pada derajat yang lebih berat nyeri dapat dirasakan terus menerus sehingga sangat mengganggu mobilitas pasien. ${ }^{1}$

Secara umum nyeri adalah suatu rasa yang tidak nyaman, baik ringan maupun berat. Nyeri didefinisikan sebagai suatu keadaan yang mempengaruhi seseorang dan eksistensinya diketahui bila seseorang pernah mengalaminya. Menurut International Association for Study of Pain (IASP), nyeri adalah pengalaman perasaan emosional yang tidak menyenangkan akibat terjadinya kerusakan aktual maupun potensial, atau menggambarkan kondisi terjadinya kerusakan. ${ }^{6}$

\section{METODE PENELITIAN}

Penelitian ini menggunakan pendekatan deskriptif kuantitatif, dimana peneliti mengembangkan konsep, menghimpun fakta dan pemahaman tetapi tidak melakukan hipotesis. Pendekatan deskriptif digunakan dengan tujuan agar penelitian ini dapat dilakukan secara mendalam sehingga mampu memberikan gambaran dan jawaban atas rumusan masalah yang ada. Waktu penelitian dilakukan bulan November - Desember 2013. 
Deu, Mogi, Angliadi; Gambaran Kejadian Nyeri Lutut...

Tempat penelitian di lakukan di BLU RSUP. Prof. Dr. R. D. Kandou Manado. Populasi adalah semua perawat di poliklinik rawat jalan RSUP Prof. Dr. R. D. Kandou. Sampel penelitian diambil dengan menggunakan rumus slovin dengan memenuhi kriteria inklusi diantaranya: tercatat sebagai perawat di poliklinik rawat jalan RSUP Prof. Dr. R. D. Kandou Manado; Bersedia sebagai subjek penelitian dan mengisi lembar kuesioner; Kriteria umur perawa $\unrhd 40$ tahun. Variabel penelitian diantaranya umur, jenis kelamin, IMT ( Indeks Massa Tubuh), Derajat nyeri (VAS), Skor Funsional (Parameter Indeks Lequesne).

Data yang dikumpulkan berupa data primer yaitu usia, jenis kelamin, tinggi badan, berat badan, kuesioner dan wawancara lansung untuk mencari informasi tertentu sebagai salah satu alat bantu memperoleh data dalam peneitian ini. Analisis data menggunakan program SPSS.

\section{HASIL}

Penelitian ini merupakan penelitian deskriptif kuantitatif yaitu dengan mengambil data primer melalui pengisian kuesioner kepada perawat di poliklinik rawat jalan RSUP. Prof. Dr. R. D. Kandou Manado selama masa penelitian dari bulan November - Desember 2013 dan di dapatkan sampel sebanyak 25 perawat yang di curigai Osteoartritis lutut. Data yang diperoleh kemudian diolah dan diuraikan berdasarkan tabel dan diagram.

Tabel 1. Distribusi perawat yang di curigai osteoartritis lutut berdasarkan umur.

\begin{tabular}{ccc}
\hline Umur & n & Persen \\
\hline 40-45 Tahun & 6 & 24.0 \\
46-50 Tahun & 5 & 20.0 \\
51-60 Tahun & 14 & 56.0 \\
Total & 25 & 100.0 \\
\hline
\end{tabular}

Tabel 2. Distribusi perawat yang di curigai osteoartritis lutut berdasarkan jenis kelamin

\begin{tabular}{cccc}
\hline \multicolumn{2}{c}{ Jenis Kelamin } & n & Persen \\
\hline \multirow{2}{*}{ Valid } & Perempuan & 23 & 92.0 \\
& Laki-laki & 2 & 8.0 \\
& Total & 25 & 100.0 \\
\hline
\end{tabular}

Tabe 3. Distribusi perawat yang di curigai Osteoartritis lutut berdasarkan IMT (Indeks Massa Tubuh).

\begin{tabular}{cccc}
\hline $\begin{array}{c}\text { Indeks Massa } \\
\text { Tubuh (IMT) }\end{array}$ & n & Persen \\
\hline \multirow{4}{*}{ Valid } & Normal & 3 & 12.0 \\
& Pre-obese & 2 & 8.0 \\
& Obese I & 13 & 52.0 \\
& Obese II & 7 & 28.0 \\
& Total & 25 & 100.0 \\
\hline
\end{tabular}

Tabel 4. Distribusi perawat yang di curigai Osteoartritis lutut berdasarkan Derajat Nyeri Lutut.

\begin{tabular}{|c|c|c|}
\hline Interpretasi VAS & $\mathbf{n}$ & Persen \\
\hline Nyeri Ringan & 19 & 76.0 \\
\hline Nyeri Sedang & 6 & 24.0 \\
\hline \multicolumn{3}{|l|}{ Valid } \\
\hline Total & 25 & 100.0 \\
\hline
\end{tabular}

Tabel 5. Distribusi perawat yang di curigai Osteoartritis lutut berdasarkan Indeks Lequesne.

\begin{tabular}{ccc}
\hline Indeks Lequesne & n & Persen \\
\hline Ringan & 13 & 52.0 \\
Sedang & 6 & 24.0 \\
Berat & 3 & 12.0 \\
Valid Sangat berat & 1 & 4.0 \\
Ekstrim & 2 & 8.0 \\
berat & & 100.0 \\
Total & 25 & \\
\hline
\end{tabular}




\section{BAHASAN}

Berdasarkan penelitian yang dilakukan pada perawat di poliklinik rawat jalan BLU RSUP. Prof. Dr. R. D Kandou Manado dengan maksud untuk mendapatkan gambaran kejadian nyeri lutut dengan kecurigaan osteoartritis lutut. Pada penelitian ini terdapat 25 perawat dan didapatkan 25 perawat yang mengalami nyeri lutut. Dapat diketahui bahwa (tabel. 2) angka kejadian osteoatritis lutut pada penelitian ini paling banyak adalah perempuan 92,0\% dan sisanya adalah lakilaki 8,0\%. Hal tersebut sama dengan hasil penelitian yang dilakukan Maria pada pasien di RSU dr. Soedarso Pontianak yang menunjukkan bahwa responden terbanyak dengan osteoatritis lutut adalah perempuan $93,96 \% .^{21}$

\section{Distribusi menurut umur}

Berdasarkan distribusi menurut umur, tabel 1 menunjukkan bahwa perawat yang di curigai OA lutut terbanyak pada kelompok umur 51-60 tahun, dimana pada kelompok umur ini terdapat 14 perawat (56,0 \%). Hal tersebut sama dengan hasil penelitian yang dilakukan Maria, bahwa prevalensi osteoartritis dalam penelitiannya pada pasien osteoartritis di RSU dr. Soedarso adalah ratatara berumur 55-73 tahun. ${ }^{21}$ Hasil penelitian ini sesuai dengan teori mengenai OA dimana penyakit ini biasanya terjadi pada umur di atas 40 tahun, karena pada umur di atas 40 tahun terjadi peningkatan kelemahan di sekitar sendi, penurunan kelenturan sendi dan semua yang mendukung terjadinya OA. ${ }^{1}$

\section{Distribusi menurut jenis kelamin}

Berdasarkan distribusi menurut jenis kelamin pada tabel 2 menunjukkan bahwa sebagian besar perawat yang di curigai OA lutut adalah perempuan yaitu sebanyak 23 perawat (92,0 \%) sedangkan laki-laki sebanyak 2 perawat (8,0 \%). Jenis kelamin merupakan salah satu faktor resiko OA.
Perempuan mempunyai kecenderungan dua kali lebih besar di bandingkan laki-laki. Perbedaan tersebut menjadi semakin berkurang setelah menginjak usia 80 tahun. Hal tersebut diperkirakan karena pada masa usia 50 - 80 tahun wanita mengalami pengurangan hormon estrogen yang signifikan. ${ }^{8}$

\section{Distribusi menurut indeks massa tubuh (IMT)}

Berdasarkan distribusi indeks massa tubuh (IMT), tabel 3 menunjukkan bahwa sebagian besar perawat adalah obese I yaitu 13 perawat (52,0 \%), obese II 7 perawat $(28,0$ $\%)$, normal 3 perawat (12,0 \%) dan pre-obese 2 perawat $(8,0 \%)$. Hal tersebut sama dengan penelitian yang dilakukan Handono, Sri, dan Faradiana pada warga yang datang ke seminar RS Baptis Batu yang menunjukkan bahwa reponden paling banyak adalah obese $53,4 \% .{ }^{22}$ Berat badan yang berlebih nyata berkaitan dengan meningkatnya risiko untuk timbulnya OA baik pada wanita maupun pria. Kegemukan ternyata tak hanya berkaitan dengan OA pada sendi yang menanggung beban. ${ }^{1}$ Semakin besar beban lemak tubuh, semakin besar trauma pada sendi seiring dengan waktu. ${ }^{10}$

\section{Distribusi menurut derajat nyeri (VAS)}

Berdasarkan distribusi menurut derajat nyeri lutut tabel 4 pada perawat yang di curigai OA lutut menunjukkan bahwa sebagian besar mengalami nyeri ringan yaitu sebanyak 19 perawat (76,0 \%). Namun hal tersebut berbeda dengan hasil penelitian Handono, Sri, dan Faradiana pada warga yang datang ke seminar RS Baptis, Batu yang menunjukkan bahwa reponden paling banyak terbanyak dengan nyeri terasa berat $53,4 \%{ }^{22}$

\section{Distribusi menurut Indeks Lequesne}

Berdasarkan distribusi menurut indeks algofungsional tabel 5 pada perawat yang 
dicurigai OA lutut menunjukkan bahwa sebagian besar indeks algofunsional ringan yaitu 13 perawat (52,0\%), sedang 6 perawat $(24,0 \%)$, berat 3 perawat $(12,0 \%)$, sangat berat 1 perawat $(4,0 \%)$ dan ekstrim berat 2 perawat $(8,0 \%)$.Namun hal tersebut berbeda dengan penelitian yang dilakukan Felicia pada pasien di unit rawat jalan RSUD. Dr. Soetomo Surabaya yang menunjukkan bahwa indeks algofunsional paling banyak adalah sangat berat. $^{23}$

\section{SIMPULAN}

Berdasarkan penelitian yang dilakukan di Poliklinik Rawat Jalan BLU RSUP. Prof. Dr. R. D. Kandou Manado 2013, dapat disimpulkan sebagai berikut:

- Jumlah perawat yang di curigai OA lutut di Poliklinik Rawat Jalan BLU RSUP. Prof. Dr. R. D. Kandou Manado 2013 adalah 25 perawat.

- Hasil penelitian berdasarkan umur menunjukkan bahwa jumlah perawat terbanyak terdapat pada kelompok umur 51-60 tahun yaitu 14 perawat (56,0\%) dan terendah pada kelompok umur 46-50 tahun yaitu 5 perawat (20,0\%).

- Hasil penelitian berdasarkan jenis kelamin menunjukkan bahwa jumlah perawat yang dicurigai OA lutut terbanyak adalah perempuan yaitu 23 perawat (92,0\%) dan terendah laki-laki yaitu 2 perawat (8,0\%).

- Hasil penelitian berdasarkan indeks massa tubuh (IMT) sebagian besar perawat obese I yaitu 13 perawat (52,0 \%), obese II 7 perawat (28,0\%), normal 3 perawat (12,0 \%) dan pre-obese 2 perawat (8,0 \%).

- Hasil penelitian berdasarkan derajat nyeri (VAS) menunjukkan bahwa sebagian besar mengalami nyeri ringan yaitu sebanyak 19 perawat (76,0 \%) dan nyeri sedang sebanyak 6 perawat (24,0\%).
- Hasil penelitian berdasarkan indeks lequesne menunjukkan bahwa sebagian besar fungsi fungsional ringan yaitu 13 perawat (52,0 \%), sedang 6 perawat (24,0 $\%)$, berat 3 perawat (12,0 \%), sangat berat 1 perawat $(4,0 \%)$ dan ekstrim berat 2 perawat $(8,0 \%)$.

\section{DAFTAR PUSTAKA}

1. Sudoyo WA, Setiyohadi B, Alwi I, K Simadibrata M, Setiadi S. Buku Ajar Ilmu Penyakit Dalam. Jilid III. Edisi V. Jakarta: Interna Publising;2009.

2. Soeroso $\mathbf{S}$, Isbagio $\mathbf{H}$, Broto $\mathbf{R}$, Pramudiyo R, Osteoartritis In: Sudoyo SW. Setiyohadi B, Alwi I, Simadibrata M, Setiati S, editors. Buku Ajar Ilmu Penyakit Dalam Jilid II Edisi IV. Jakarta: Fakultas Kerdokteran Universitas Indonesia, 2006; p.1195-201.

3. Smeltzer SC, Bare BG. Buku ajar keperawatan medikal bedah Brunner and Suddarth ( ${ }^{\text {th }}$ Edition): editor, Suzanne C. Smeltzer, Brenda G. Bare; alih bahasa, Agung Waluyo, dkk; editor edisi bahasa Indonesia, Monica Ester, Ellen panggabean. Jakarta: EGC; 2001.

4. Billiantono H. Penanganan Praktis Osteoartritis. Jakarta: Halimun Medical Center, 2009; p.7-15.

5. Kumar, Cotran, Robbins. Buku Ajar Patologi Vol 1 (Ed 7) . Jakarta: EGC, 2007; p.341-342.

6. Arissa IM.Pola Distribusi Kasus Osteoatritis di RSU Dr. Soedarso Pontianak.Naskah Publikasi; 2009.

7. Kalim H, Andarini S, Rasyidi F. Hubungan IMT (Indeks Massa Tubuh) dengan Derajat Nyeri Pada Penderita Osteoartritis Lutut pada warga yang datang Seminar di RS Baptis Batu [Skripsi]. Malang: FK Brawijaya; 2010

8. Hartono F. Gambaran Pengukuran Algofungsional dengan Kuesioner Lequesne Pada Osteoartritis Lutut [Skripsi].Surabaya; 2011. 